\title{
Hydroponic System with Automated Hydrolysis Using Renewable Energy Self-Sustainable
}

\author{
Felipe Jaimes, Brayan Collazos, Emerson Arce, Mario Chauca \\ FIEE-UNAC Universidad Nacional del Callao, Juan Pablo II 306, Bellavista 07011 Callao, Perú
}

\begin{abstract}
Implement a system in which the variables of temperature, humidity, luminosity, $\mathrm{CO} 2$ and $\mathrm{PH}$ developing it in a crop hydroponic that guarantees the survival of the plant. In addition to monitoring and controlling pests that could affect the plant. Through an automated system with renewable energy. Obtaining energy with solar and wind panels. Also accumulate rainwater for watering the plants. Thus achieving a self-sustainable system, with better quality products and cultivate all kinds of food on any day of the year.
\end{abstract}

\section{Introduction}

The crops under greenhouses have allowed over the years to have good quality products, extending the cultivation cycle, allowing production in places of difficult conditions, obtaining not only quality, but also quantity. In addition, crops without soil, hydroponics (work in water) or Aerophobia should be taken into account, although they have time for research and implementation are little known methods of agricultural production and is a center of attraction for many people who want to cultivate their crops. Fresh vegetables, without worrying about excess fertilization, pesticides, weather, and land problems, etc., bring many advantages, such as: [1].

-Saving water

- Automated handling

- Saving work

- Savings in the use of substrates

- Greater production in less space

- Less loss in the use of fertilizers. Only the necessary ones are used.

- Greater profits with less investment.

The automation of greenhouses is already very popular in different countries, since a high percentage of the crops are lost due to the carelessness of the personnel who have to watch the plantings 24 hours a day [2].

These are some examples of common oversights:

- Dehydrated plant: for not watering in time and in shape.

- Drowned plant: due to excessive irrigation.

- Plants with little growth: for not having an automatic nutrition system.

- Asphyxiated plants: due to excess temperature due to the fact that they do not open the curtains at noon.

- Plants burned: for not closing the curtains or turning on the heaters in frosts.
- plants with pests: due to the fact that in a storm the curtains were broken by not closing them properly or by leaving the greenhouse open doors without access control. (Automation, control and monitoring of greenhouses, 2015) [3]

The idea of an automated hydroponic greenhouse offers many Benefits; how to develop a auspicious environment for the development of any crop that adapts to the nutrition system through the root and not only save time in the management of the crop, also space, since the land becomes more expensive every day and the land for planting is limited, worn and contaminated, that's when hydroponics is offered as an important alternative to generate more

Production in less space and without the danger of contamination and we must not forget that water and energy are saved, there will be less loss in the use of fertilizers, reducing costs and increasing profits. [4]

Obtaining an optimal water saving through the electrolysis process we will achieve this based on the water tanks that we will get as a result of rains, in turn with a solar panel that will act with a microcontroller that will activate the electro valves to be able to perform this operation these electro valves are activated by feeding them with an electric potential generating a magnetic field and thus act on the plunger they have to act in a way that prevents or does not pass the fluid. [5]

In addition, you can also see the nutrients, as we are in a floating root hydroponics system we will initially add the nutrient solution (more mineral water) and then we will only add water until we find a change in the volume of the solution or in turn in the $\mathrm{PH}, \mathrm{CE}$. [6]

As well as this is an open hydroponic system since through peripheral pumps we will circulate the water, we have 4 containers which are under the list of nutrient $\mathrm{A}$, nutrient $\mathrm{B}, \mathrm{pH}$ Down, $\mathrm{pH}$ UP. [7]

Nutrients $\mathrm{A}$ and $\mathrm{B}$ are added depending on the amount of water to circulate, with the proportion of $5 \mathrm{ml}$ 
of concentrated solution greater than $\mathrm{A}$ and $2 \mathrm{ml}$ of concentrated solution lower B (this will be explained below in the procedure).

Since the European and non-European countries have adopted a series of market support mechanisms ranging from simple bonuses per electric unit produced by renewable energy plants to more complex mechanisms that force electric generators to obtain an increasing percentage of supplies from renewable energy [8].

\subsection{Hybrid solar technology}

Combine solar energy with other energy. Depending on the energy with which it is combined, it is a hybridization: renewable (biomass, wind energy) or nonrenewable (fossil fuel).

Many hybrid systems are autonomous and operate outside the network, not connected to an electricity distribution system. For times when neither the wind nor the solar system is producing, most hybrid systems provide power through batteries and / or an engine generator powered by conventional fuels, such as diesel. If the batteries are depleted, the motor generator can supply power and recharge the batteries. [9] The use of solar panels considering Irradiation values according to geographical location as shown in Table 1 and wind in this project is no stranger. For this we show Fig1-2.

Table 1. Irradiation values according to geographical location. [12]

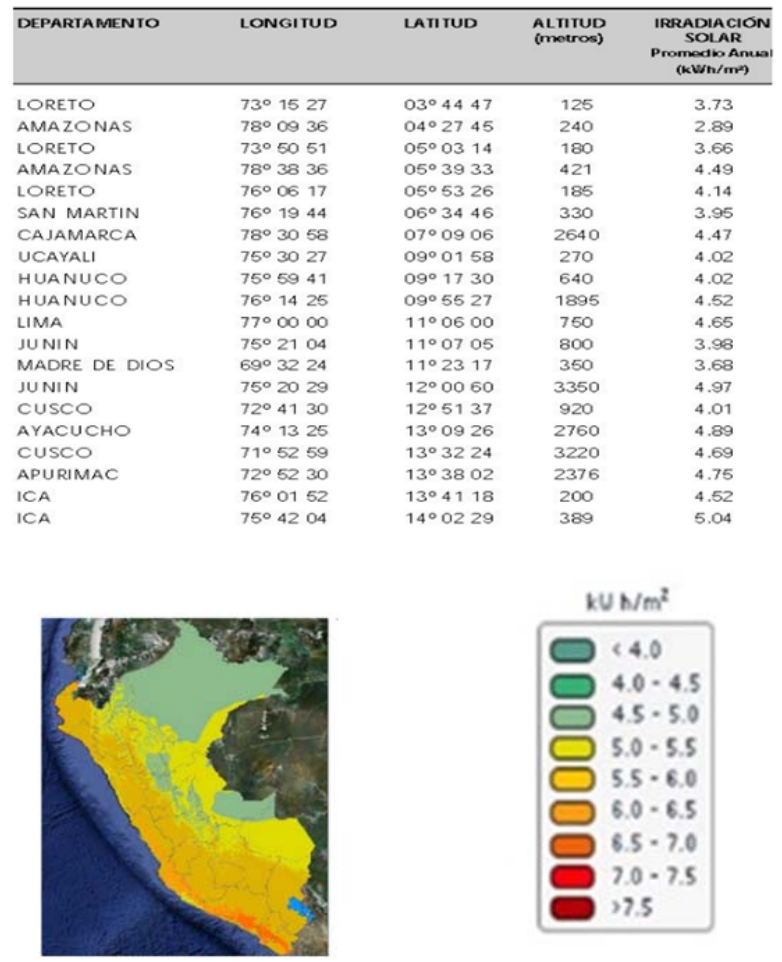

Fig. 1. Irradiation reading map for the use of solar panels in Peru. [10]

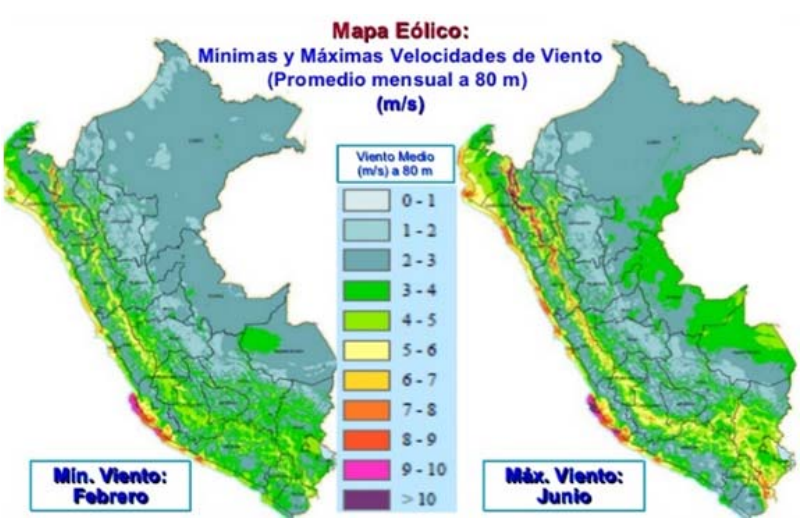

Fig. 2. Wind map in Peru. [11]

\subsection{Conditions to keep in a Greenhouse}

An essential feature of the greenhouse is based on the climate of the area to generate the design without forgetting the orientation of this looking that is malleable, economical and that supports the crop with all the necessary equipment to satisfy the physiological needs. [13]

As:

Water: element whose function is to control the temperature of the plant and mobilize the nutrients that implies.

- Irrigation system (localized, nebulization and spray)

- Automation of the irrigation system [14]

Nutrition:

- Fertilization or fertigation [15]

Relative humidity: essential factor for temperature control, to maintain it is used:

- Irrigation by nebulization.

- Wet walls. [16]

Temperature: factor that affects the efficient development of the plant to control it from the climate we can use:

- Thermo-hygrometers: it allows you to know the temperature inside the greenhouse.

- Extractors, heaters, fans.

- Plastic shading meshes (coverage)

- Antiafidos mesh, zenithal windows [17]

Ventilation: It is the renewal of the air inside the greenhouse in order to provide $\mathrm{CO} 2$ necessary for the development of the crop and lower the internal temperature.

- Place vents with three possibilities to do so:

1.In the upper part of the greenhouse (roof vents)

2. On the sides (side vents)

3. On the top of the fronts or later (front vents). The vents should be protected against antiafidos meshes to prevent the passage of insects and birds [18]

\section{Process}

\subsection{Definition of the problem}

Analysing the form of growth of the crop, according to its time of maturation and also the infestation to them by 
pests, samples are taken by a digital camera and in MATLAB communication to later process some information and obtain a diagnosis either for the suggestion of insecticides, irrigation, fertilizers, size of cultivated products, etc.

\subsection{Operation}

- A database is saved taking the final product and in good condition (in this case lettuce) we shown in Fig3-4.
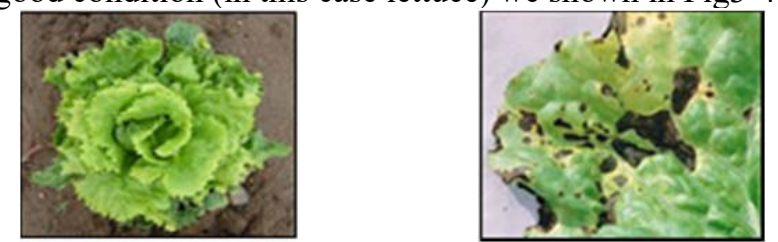

Fig. 3. Lettuce in good condition. Fig. 4. Lettuce in terrible conditions.

Using the MATLAB tool for this purpose we have to process the images taking RGB patterns, shown in Fig 5.

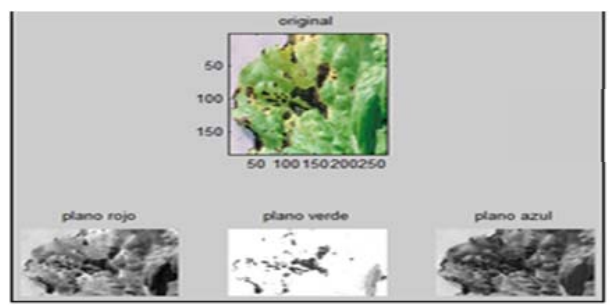

Fig. 5. Planes R, G, B.

- Samples are taken, good and bad parts of each portion are identified, as shown in Figure 6.

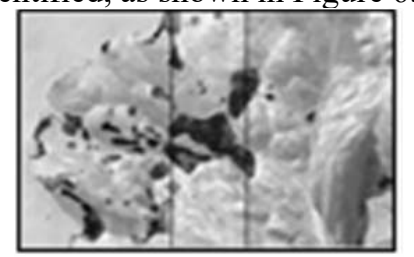

Fig. 6. Signaling of analyzed parts.

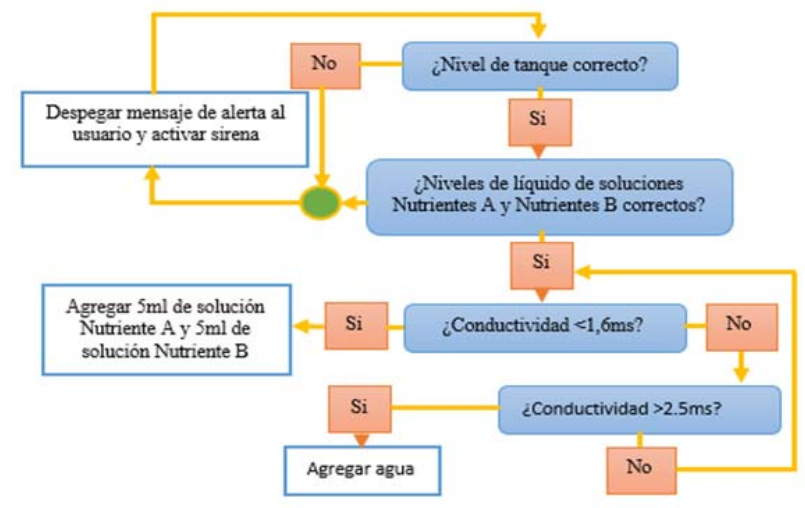

Fig. 7. Electric conductivity control.

As shown in Figure 7, thanks to the module "MinieC" [19], the module delivers a digital signal of 12 bits through the I2C bus [20] to our controller in this case Arduino which will facilitate communication avoiding the use of many pins with the sensor EC-451. As in the $\mathrm{PH}$ we will perform a reading of 50 data and we will obtain an average of these and apply the following adjustment formula to obtain the conductivity value:

$\mathrm{EC}(\mathrm{mS})=($ average $* 32.194)-1476.746$

What allows dosing control as shown in Fig.8.

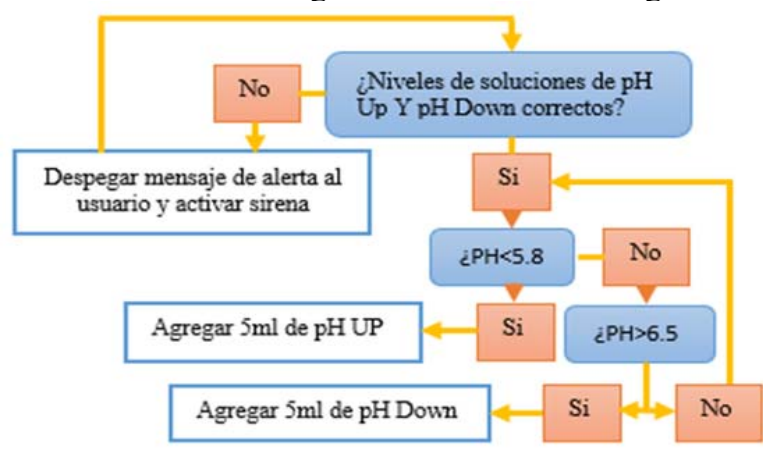

Fig. 8. Dosing control.

Through this subsystem, the $\mathrm{pH}$ levels are read. The $\mathrm{pH}$ module is read from an analog port, therefore, a value between $0 \mathrm{~V}$ and $5 \mathrm{~V}$ is obtained, 50 data is read and an average of these is obtained, applying the following formula to obtain the $\mathrm{pH}$ value:

$\mathrm{pH}=$ average* $17.5 / 1024$

Thanks to the "Analog pH Meter Pro" kit [21] that

includes an industrial sensor with precision of \pm $0.1 \mathrm{pH}$ at $25^{\circ} \mathrm{C}$ and that the manufacturer also specifies that it can remain submerged in the fluid in this case water for long periods, together with a transmitter that delivers the scaled signal of $05 \mathrm{VDC}$ for a $\mathrm{pH}$ range of 0 to 14 [22]. The transmitter also has a gain adjustment potentiometer for calibration in alkaline or acid solutions.

During the development stage, monitoring by relative humidity is important because very low temperatures decrease the metabolism and the development of the plant, which would delay the harvest, very high temperatures with low relative humidity increase the evapotranspiration rates and can cause dehydration [23], for this we use DHT22 sensor allows you to monitor temperature and relative humidity accurately and easily. The output is digital type. [24], as shown in Fig. 9-10, according with formula:

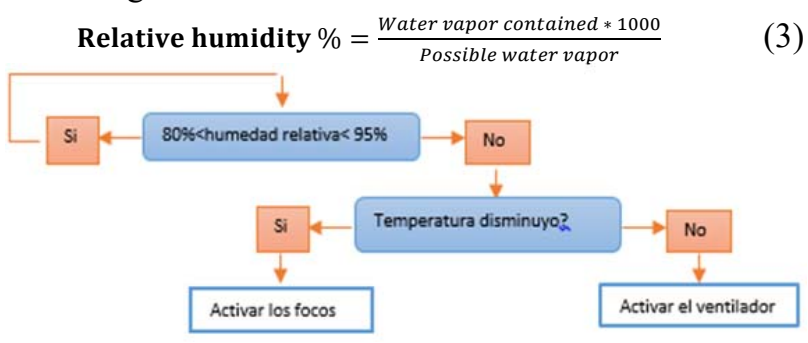

Fig. 9. Monitoring of Temperature and Relative Humidity within the Greenhouse. 

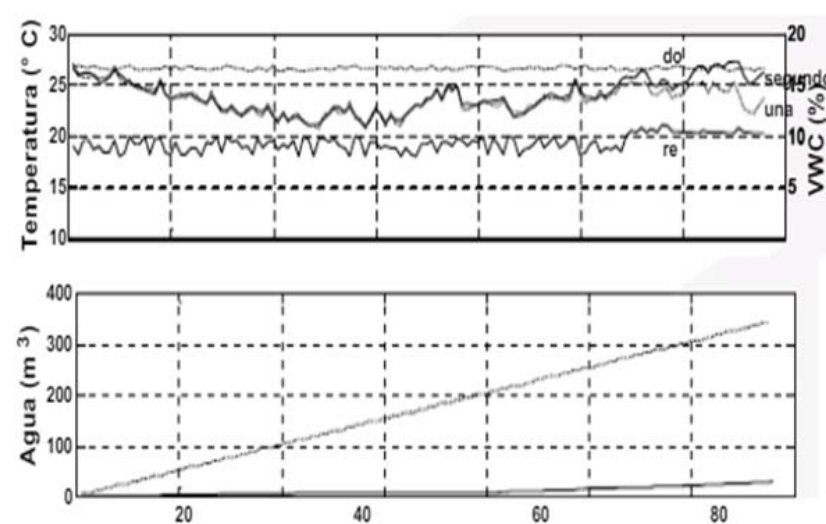

Fig. 10. Variation of Temperature and Humidity values. [25]

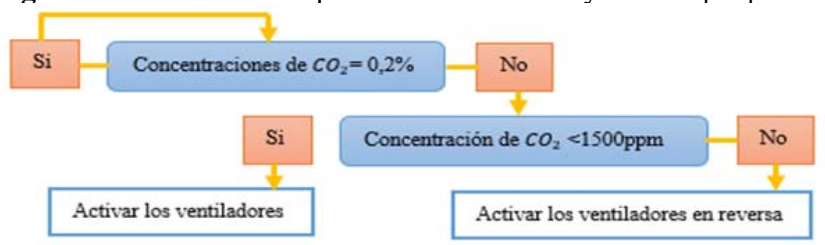

Fig. 11. $\mathrm{CO} 2$ monitoring.

As shown in Figure 11, The concentration of the normal $\mathrm{CO} 2$ in the atmosphere is $0.03 \%$ should be increased to limits of $0.1 \%-0.2 \%$ thanks to this we will reduce the time of the harvest with the help of the MQ135 sensor. [26] Through the formulas

$$
\begin{gathered}
R_{S}=\frac{V_{C}-V R_{L}}{V R_{L}} \times R_{L} \\
p p m=113,7105 \times\left(\frac{R_{S}}{R_{0}}\right)^{-3,0197}
\end{gathered}
$$

Allowing design the electronic diagram of the system and block diagram as shown in Fig.12-13.

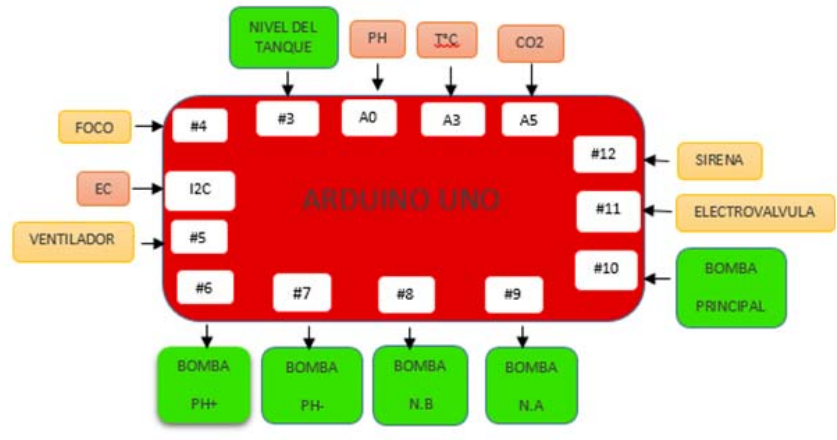

Fig. 12. General electronic diagram of the System.

\section{Programmed Logic}

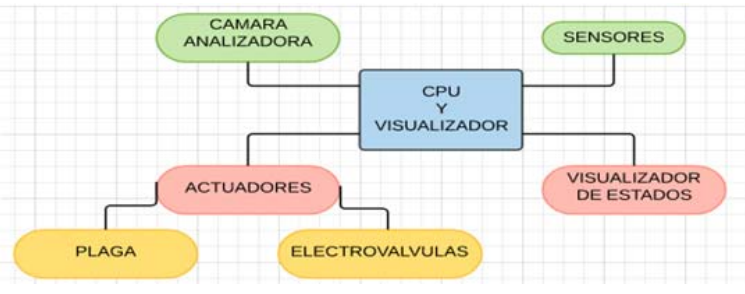

Fig. 13. Block diagram.

\%llamado de imagen $\mathrm{a}=$ imread('lechugam.jpg');

$\%$ extraccion de planos

ar $=\mathrm{a}(:,:, 1)$; $\mathrm{ag}=\mathrm{a}(:,:, 2)$;

$\mathrm{ab}=\mathrm{a}(:,:, 3)$;

$\%$ despliegue

image(a)

figure(1),subplot(2,3,2),image(a),title('original')

figure(1),subplot(2,3,4),imshow(ar),title('plano rojo')

figure(1), subplot(2,3,5),imshow(ag*2), title('plano verde')

figure(1), subplot(2,3,6),imshow(ab),title('plano azul')

ag_recorte $=\mathrm{ag}(:, 100: 120) * 2$;

ag_recorte $2=\mathrm{ag}(:, 150: 170) * 2$;

figure(2), subplot(1,2,1),imshow(ag recorte)

figure(2),subplot(1,2,2),imshow(ag_recorte2)

$\mathrm{pl}=\mathrm{ag}(:, 111)^{*} 2$;

$\mathrm{pl} 2=\operatorname{ag}(:, 230) * 2$;

grid on

figure(3), subplot(1,2,1),plot(pl)

figure(3), subplot(1,2,2),plot(pl2)

$\operatorname{ag}(:, 111)=0$;

$\operatorname{ag}(:, 167)=0$;

figure(4),imshow(ag)

indexmin $=\operatorname{find}(\min (\mathrm{pl})==\mathrm{pl})$;

$\mathrm{ymin} 1=\mathrm{pl}($ indexmin)

indexmin $=$ find $(\min (\mathrm{pl} 2)==\mathrm{pl} 2)$;

$\mathrm{ymin} 2=\mathrm{pl}$ (indexmin)

$[\mathrm{m}, \mathrm{n}]=\operatorname{size}(\mathrm{ymin} 2)$;

disp('la lechuga $1: ')$

if $($ ymin $1<90)$

disp('la lechuga no esta apta:')

disp('se sugiere reducir humedad ')

else disp('la condicion de cuidado es excelente')

end

disp('la lechuga 2(a comparar siempre):')

if $(\mathrm{ymin} 2<90)$

disp('la lechuga no esta apta:')

disp('se sugiere reducir humedad ')

else disp('la condicion de cuidado es excelente')

end

grid on;

$\mathrm{a}=$ imread('NEW IMAGEN);

ar=a(:,:,1);

$\mathrm{ag}=\mathrm{a}(:,:, 2)$;

$\mathrm{ab}=\mathrm{a}(:,:, 3)$;

\%despliegue

image(a)

figure(1),subplot(2,3,2),image(a),title('original')

figure(1),subplot(2,3,4),imshow(ar),title('plano rojo')

figure(1),subplot(2,3,5),imshow(ag*2), title('plano verde')

figure(1),subplot(2,3,6), imshow(ab),title('plano azul')

\section{Results}

The naked eye comparisons of the lettuce table are very noticeable, in the axis of the variation of the colour, its minimum of 28 in the lettuce of bad state; compared to the 224 that has the lettuce in good condition as shown in Fig. 14 and Table 2. 


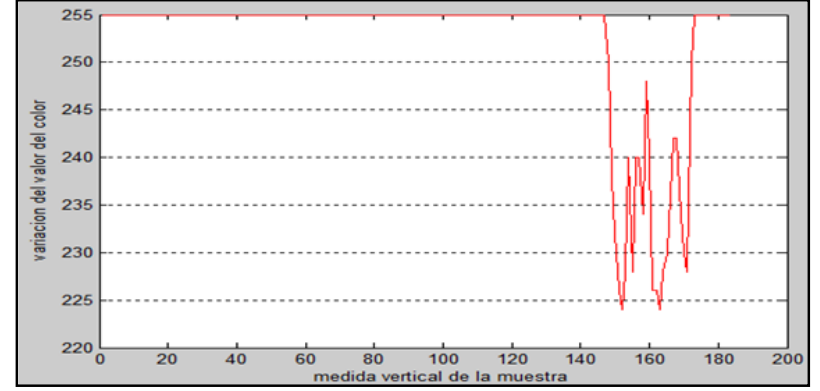

Fig. 14. Graph obtained in Matlab of the lettuce in good condition.

Table 2. Values obtained in the graph (Lettuce in good condition).

\begin{tabular}{|c|c|c|c|c|}
\hline & $x$ & & $\mathbf{Y}$ & \\
\hline $\min$ & 1 & 且 & 224 & $\square$ \\
\hline $\max$ & 183 & $\square$ & 255 & 晋 \\
\hline mean & 92 & 回 & 252.2 & 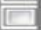 \\
\hline median & 92 & $\square$ & 255 & 且 \\
\hline mode & 1 & $\square$ & 255 & 且 \\
\hline std & 52.97 & 四 & 7.625 & \\
\hline range & 182 & & 31 & \\
\hline
\end{tabular}

The maximum value data is 255 in them because in the analysis of the green plane is the maximum value, from there is the starting point until it is degraded until it reaches zero which is black and that is the value that gives us a more infected lettuce as shown in Fig.15 and Table 3.

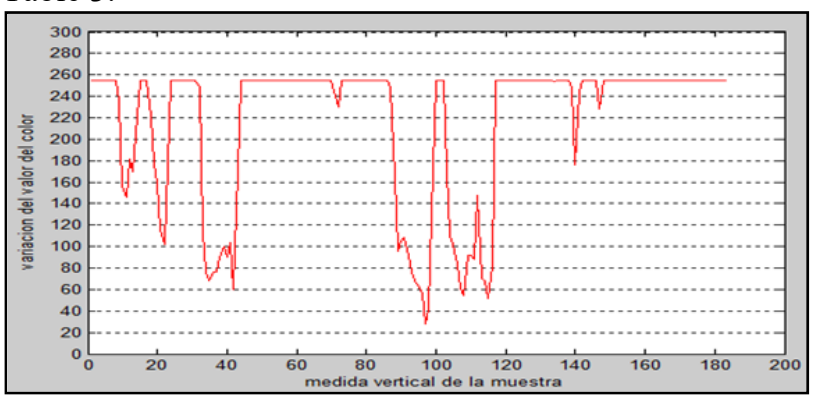

Fig. 15. Graph obtained in Matlab of the lettuce in bad condition.

Table 3. Values obtained in the graph (Lettuce in poor condition).

\begin{tabular}{|c|c|c|c|c|}
\hline & $x$ & & $Y$ & \\
\hline $\min$ & 1 & 回 & 28 & \\
\hline $\max$ & 183 & 回 & 255 & \\
\hline mean & 92 & $\square$ & 215.3 & \\
\hline median & 92 & 回 & 255 & \\
\hline mode & 1 & $\square$ & 255 & \\
\hline std & 52.97 & 回 & 68.85 & D \\
\hline range & 182 & & 227 & \\
\hline
\end{tabular}

These data are taken and analysed by the same program which gives us a friendlier interface to understand the data, at automation level these data activate actuators.

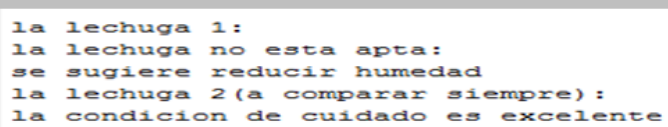

Fig. 16. Information shown by analysis.

As shown in Figure 16 and 17, For the project to be self-sustainable we use renewable energy and we combine different types of renewable energy to what we call Solar-Hybrid energy which was described at the beginning of said document.

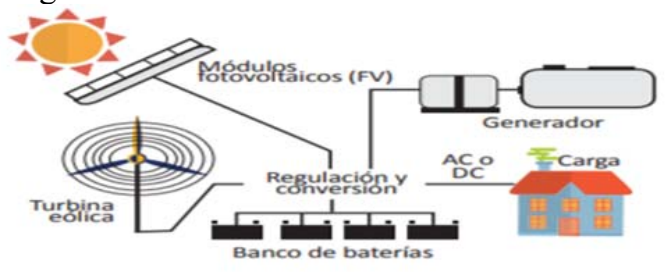

Fig. 17. Solar-Wind Hybrid Energy System. [27]

As shown in table 4-5, to have an optimal crop development, you should monitor and take action on the parameters. For which we make a table for the different cases that may arise:

Table 4. Parameters of crop development control.

\begin{tabular}{|c|c|c|}
\hline DESCRIPTION & VALUE & $\begin{array}{l}\text { ACTIONS TO BE } \\
\text { CARRIED OUT }\end{array}$ \\
\hline $\mathrm{T}^{\circ}$ increases & H.R $<80 \%$ & Activate the fan \\
\hline$Y^{\circ}$ decreases & H.R $>95 \%$ & Activate the spotlights \\
\hline CO2 decreases & $\mathrm{CO} 2<0,2 \%$ & Activate the fan \\
\hline $\mathrm{CO} 2$ increases & $\mathrm{CO} 2>0,2$ & $\begin{array}{l}\text { Activate the fan } \\
\text { opposite direction }\end{array}$ \\
\hline
\end{tabular}

Table 5. Values for actuation of the actuators.

\begin{tabular}{|c|c|c|}
\hline DESCRIPTION & VALUE & $\begin{array}{l}\text { ACTIONS TO BE } \\
\text { CARRIED OUT }\end{array}$ \\
\hline \multirow[t]{2}{*}{ Minimum EC } & $<1.6 \mathrm{mS} / \mathrm{cm}$ & $\begin{array}{l}\text { Add } 5 \mathrm{~cm} 3 \text { of Nutrient A and } \\
5 \mathrm{~cm} 3 \text { of Nutrient B }\end{array}$ \\
\hline & $>2.5 \mathrm{mS} / \mathrm{cm}$ & $\begin{array}{l}\text { Turn on Alert LED. It is } \\
\text { necessary to add water. User } \\
\text { intervention required. Dosage } \\
\text { can not be done. }\end{array}$ \\
\hline EC Maximum & $<5,8$ & Add $5 \mathrm{~cm} 3$ of liquid $\mathrm{pH} \mathrm{Up}$ \\
\hline Minimum pH & $>6,5$ & Add $5 \mathrm{~cm} 3$ of liquid $\mathrm{pH}$ Down \\
\hline Maximum pH & Low & $\begin{array}{l}\text { Turn on Alert LED. User } \\
\text { intervention required. } \\
\text { Pumping or dosing can not be } \\
\text { done }\end{array}$ \\
\hline Water level & Low & $\begin{array}{l}\text { Turn on Alert LED. User } \\
\text { intervention required. PH } \\
\text { dosing can not be done. }\end{array}$ \\
\hline PH level UP & Low & $\begin{array}{l}\text { Turn on Alert LED. User } \\
\text { intervention required. PH } \\
\text { dosing can not be done }\end{array}$ \\
\hline PH level Down & Low & $\begin{array}{l}\text { Turn on Alert LED. User } \\
\text { intervention required. } \\
\text { Nutrients can not be dosed }\end{array}$ \\
\hline Nutrient Level A & Low & $\begin{array}{l}\text { Turn on Alert LED. User } \\
\text { intervention required. } \\
\text { Nutrients can not be dosed }\end{array}$ \\
\hline Level of Nutrient B & $15^{\circ} \mathrm{C}<\mathrm{T}<25^{\circ} \mathrm{C}$ & $\begin{array}{l}\text { place thermal insulators to the } \\
\text { water reservoir }\end{array}$ \\
\hline
\end{tabular}

\section{Conclusions}

When we do the decomposition of the color plane we must focus on what problem the lettuce will attack since it will depend on the plague to obtain characteristic parameters.

Irrigation is registered by standard parameters of lettuce, so these are regulated by automation and filtered by hydrolysis.

When the values were out of range, the control will act under the established parameters, first stabilizing the conductivity and then the $\mathrm{pH}$.

With the fulfillment of these parameters we avoid diseases to the plants in this case lettuces which at an incorrect $\mathrm{pH}$ value do not grow as they should be, 
likewise they would develop toxicity as fungi and die quickly because they would not absorb nutrients well and they would not have much oxygen.

This control and automation system not only allows to control the $\mathrm{pH}$, conductivity and temperature levels of the nutritive solutions, it also allows to register these values constantly creating a register of all the variables throughout the production process, which becomes an important source of information to improve the quality of future productions.

The system works to maintain the vegetables without the need for constant intervention by the user without any nutritional stress, which will be reflected in a better production and therefore in better utilities for the producer.

\section{Observations}

It must be taken into account that the way of taking the photo can influence the results, so first you have to take the parameter and the conditions and work on them so as not to alter the results.

The green plane should be adjusted to comfort according to the type of lettuce or plantation one wishes to analyse.

\section{References}

1. «Design and implementation of an automated hydroponic greenhouse system» Omar Rojas Cardona Jessica Zulaydi Vaca Lozano Yeison Adalbert Vaca Lozano, 2016.

2. Jorge Arce Portuges, Hydroponic and Organoponic Crops 2015.

3. Design of an automated greenhouse with vertical hydroponic cultivation of lettuce in Mexico, Tesina, Cruz Ramírez Rodolfo Agustín 2015

4. Cultural practices of integrated control in greenhouses, Oscar Alomar, Joaquin Adillon, Enriqueta Bordas, Cristina Castañe, Rosa Gabarra and Ramon Albajes, 2015

5. Cultivation in hydroponics, José Beltrano and Daniel O. Gimenez, 2016

6. Hydroponic production manual for leafy vegetables 2014 system.

7. Jorge Arce Portuges, Hydroponic and Organoponic Crops 2015.

8. The Electricity Industry in Peru - Capitulo5 PeruNatural Energy Source, Non-Conventional Natural Resources - Osinergmin, 2016

9. Savings and Energy Efficiency in Greenhouses, Government of Spain, Ministry of Industry and Tourism 2016

10. The Renewable Energy industry in Peru Osinergmin, 2017
11. Atlas Eolico del Peru, Ministry of Energy and Mines of Peru

12. Atlas of Solar Energy in Peru, Ministry of Energy and Mines - Senamhi

13. Greenhouse Automation for Hydroponic Crops in El Salvador, Tec. Josué Alberto Pérez Zavala Tec. Leonel Eduardo López Guevara Tec. René David Romero Vásquez, July 2016.

14. Automatic drip irrigation system using a wireless sensor network, Efrain Mayhua Lopez, Jhimy Ludeña, Jorge Tamayo, 2016

15. Plant Nutrition, Agronomist Dr. Fernando Ramos, Aguas Calientes Autonomous University, Unit I, Nutrients in Plants, 2015

16. Monitoring of temperature and humidity of greenhouses with Arduino, Miguel Ángel Barrera Valdés; Lic. Julián Omar Baltazar Hernández; José Rebrindanard Rubalcava López, Higher Technological Institute P'urhépecha 2015

17. Climate control in greenhouses, Jhon Favia Acuña Caita, ISBN: 978-958-719-215-5, Editorial Universidad Nacional de Colombia. Options Gráficas Editores Ltda.

18. Refrigeration system in a mesh greenhouse: effects on the microclimate, productivity and responses of the plants of a tomato crop, Rocio Leyva Jimenez, Granada Thesis 2016

19. Naylamp mechatronics [Online].

20. «Mini EC Interface,» Sparky's Widgets, [Online].

21. «Analog pH Meter Pro,» DF Robot, [Online]

22. Design and implementation of a pH control, conductivity and water level monitoring for the care of hydroponic crops for domestic use, A. Amaya, L. Cruz 2016

23. Savings and Energy Efficiency in Greenhouses, Government of Spain, Ministry of Industry and Tourism 2016

24. Book of Science and Technology No. 2 Technological Studies of Ecatepec 2016.ISBN 978607-95065-0-6.

25. Technification and implementation of three methods of hydroponics, SERGIO NICOLAS ECHEVERRI GONZALEZ 2016

26. Eliseo Sebastián, Consultant in Environmental Management. (solar energy and photovoltaic systems)

27. Gas sensor module MQ-135 - mq-135 gas sensor, Fast response and High sensitivity, Simple drive circuit, Wide detecting scope, Stable and long life [online]

28. The Renewable Energy industry in Peru Osinergmin, 2017, Chapter 01 - RER Technologies and New Energy Trends, Page 35. 